\title{
Effect of the synthesis conditions on the properties of Co embedded porous Si nanostructures
}

\author{
A. Çetinel ${ }^{\mathrm{a}, *}$, N. Artunç̧ $c^{\mathrm{a}}, \mathrm{E} . \operatorname{Tarhan}^{\mathrm{b}}$ \\ ${ }^{a}$ Department of Physics, Ege University, Bornova 35100, Izmir, Turkey \\ ${ }^{\mathrm{b}}$ Department of Physics, Izmir Institute of Technology, Urla 35430, Izmir, Turkey
}

\section{A R T I C L E I N F O}

\section{Keywords:}

Porous silicon

Cobalt nanoparticles

Electrodeposition

Photoluminescence

Passivation

\begin{abstract}
A B S T R A C T
The electrodeposition of cobalt in the porous silicon (PSi) substrate was investigated in terms of the deposition times and current densities. The PSi/Co samples were characterized by SEM, XRD, Raman, and photoluminescence (PL) spectroscopies. The results indicated that for all current densities, the PL intensities of PSi/Co samples with shorter deposition times $\left(t_{s} \leq 20 \mathrm{~min}\right.$ ) increased due to spherical Co nanoparticles (NPs) could be created the new recombination centers, compared to that of the undeposited PSi. On the other hand, the PL intensity of PSi/Co samples significantly decreased at longer deposition times $\left(t_{1}>20\right.$ min) because of larger Co NP cluster promoted the formation of non-radiative centers. The increased PL intensities in samples with $t_{s}$ were attributed to both the quantum confinement effect and surface effects. PL analyses also suggested that after exposure to air for 60 days, PL characteristics of PSi/Co were stabilized depending on deposition time and current density.
\end{abstract}

\section{Introduction}

Tunable and highly efficient, room temperature photoluminescence of porous silicon (PSi) and its compatibility to the wide-spread silicon technology have made it a very attractive material for potential applications in optoelectronics, chemical sensing and biomedical fields [1]. In addition to its unique photoluminescence (PL) properties, the extremely large surface area, the ease of its formation and controllability of the surface morphology with the formation parameters are the other interesting features of PSi. But, as well known, the metastable siliconhydrogen (Si-H) bonds in PSi matrix are easily broken by oxygen in the ambient atmosphere which results in the degradation of surface chemistry and instability of optical characteristic in PSi [2]. Due to the outstanding instability problem of PSi, passivation of its surface is necessary to develop porous silicon-based optoelectronic devices.

In order to improve PL intensity of PSi as well as to passivate its surface, substitution of surface hydrogen by transition metals has attracted a considerable attention in the last decade [3-10]. However, a limited number of studies, dealing with structural analysis and the light emitting properties of $\mathrm{PSi} / \mathrm{Co}$ by electrodeposition were reported in literature as compared to the many reported works about PSi structures deposited with other transition metals such as iron and nickel [3-5]. Among a few works on Co deposited PSi, for example, Zeng et al. [8] investigated morphologies and chemical properties of Co passivated PSi obtained by stain etching. In another work, the magnetic and PL properties of the Co embedded PSi samples, prepared by the electroinfiltration method, were studied by Noval et al. [9]. In that study, the biocompatibility and nontoxicity of PSi/Co were also assessed. Rumpf et al. [11] studied the effect of current density on the structural and magnetic properties of cobalt deposited PSi obtained by electrodeposition. In a more recent work, Bouzourâa et al. [6] reported the effects of annealing temperature and immersion duration on PL characteristics of cobalt-porous silicon nanocomposites prepared via immersion method. Taking into account the findings of such studies $[6,8,10]$, we suggest that due to its high protection ability against oxygen and high thermal stability, cobalt (Co), among all the transition metals, may be the best candidate for a deposition material to achieve an efficient and stable PL from PSi.

$\mathrm{PSi} / \mathrm{Co}$ nanostructures can be produced by a variety of techniques such as immersion method, stain etching, and electrodeposition $[6,8,11]$. Among these techniques, electrodeposition provides the ability to tailor size, shape, and morphology of the Co deposited under a set of well controlled synthesis parameters [12]. It is also important to note that the surface morphology and optical properties of Co nanostructures on PSi depend sensitively on the parameters of electrodeposition. Accordingly, the aim of the reported work is to investigate how structural, morphological and PL properties of PSi/Co nanostructures vary with the Co nanoparticles deposited via the

\footnotetext{
* Corresponding author.

E-mail address: alper.cetinel@ege.edu.tr (A. Çetinel).
} 

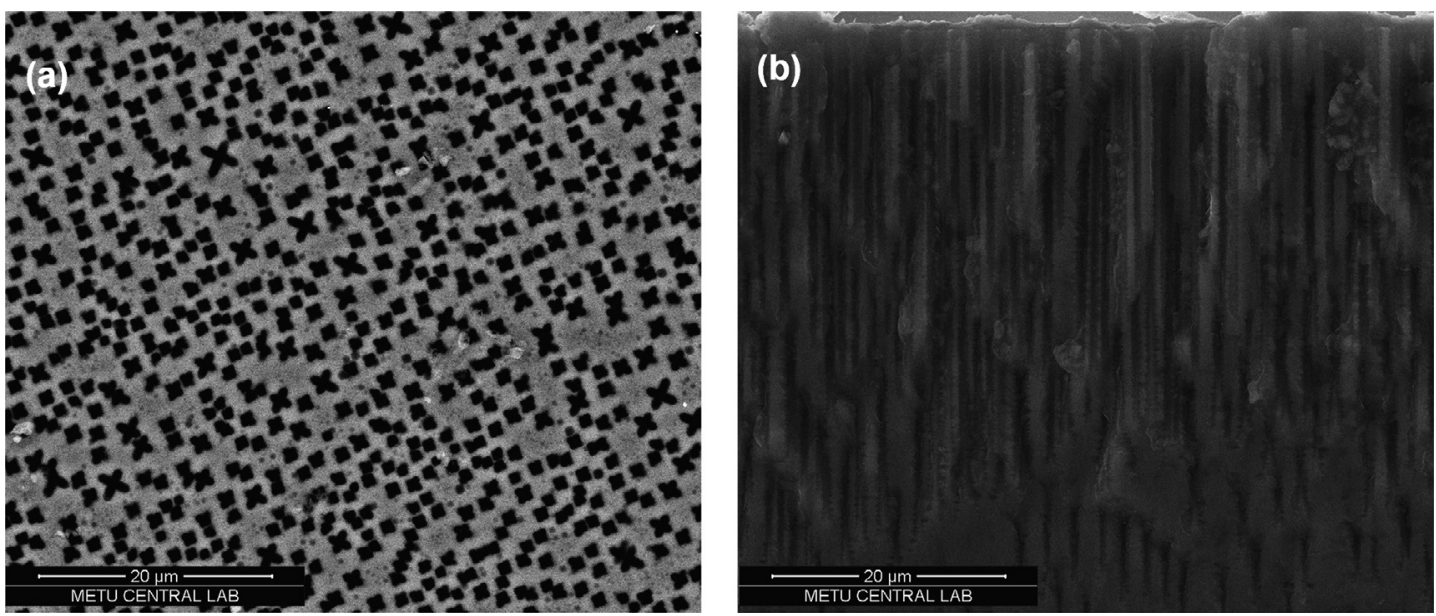

Fig. 1. FE-SEM images of a PSi sample prepared in $20 \% \mathrm{HF}$ concentration at $60 \mathrm{~mA} / \mathrm{cm}^{2}$ for $30 \mathrm{~min}$ by using the anodization method, (a) top-view, (b) cross-section image.
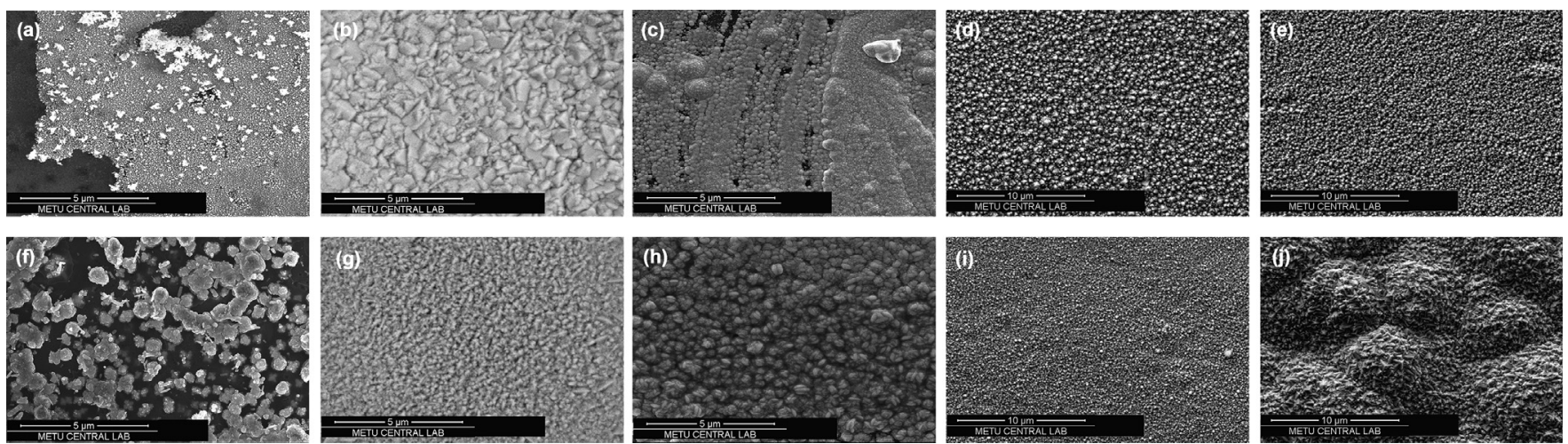

Fig. 2. Top-view FE-SEM images of PSi/Co nanostructures deposited at $0.1 \mathrm{~mA} / \mathrm{cm}^{2}$ for (a) $5 \mathrm{~min}$, (b) $10 \mathrm{~min}$, (c) $15 \mathrm{~min}$, (d) $30 \mathrm{~min}$, and (e) $60 \mathrm{~min}$; at $0.2 \mathrm{~mA} / \mathrm{cm}^{2}$ for (f) $5 \mathrm{~min}$, (g) $10 \mathrm{~min}$, (h) $15 \mathrm{~min}$, (i) $30 \mathrm{~min}$, and (j) $60 \mathrm{~min}$.
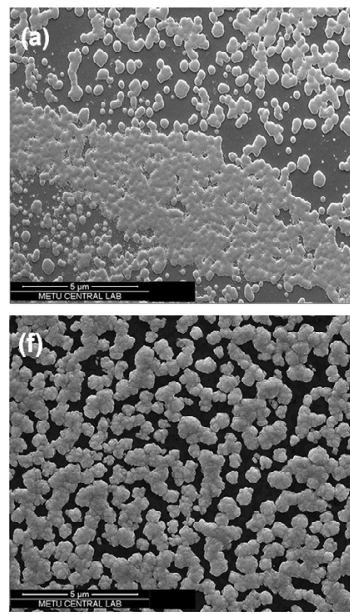
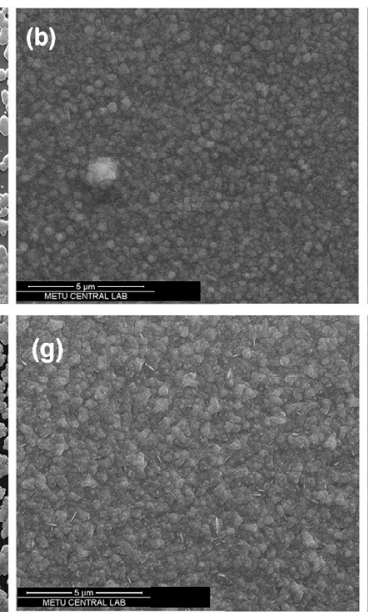
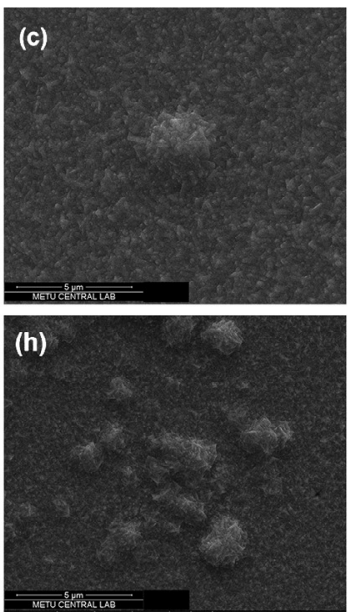
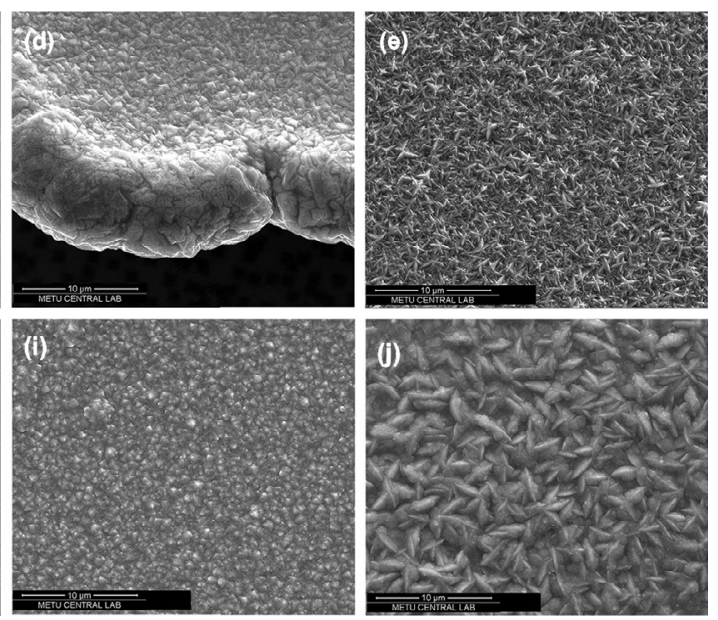

Fig. 3. Top-view FE-SEM images of PSi/Co nanostructures deposited at $0.3 \mathrm{~mA} / \mathrm{cm}^{2}$ for (a) $5 \mathrm{~min}$, (b) $10 \mathrm{~min}$, (c) $15 \mathrm{~min}$, (d) $30 \mathrm{~min}$, and (e) $60 \mathrm{~min}$; at $0.5 \mathrm{~mA} / \mathrm{cm}^{2}$ for (f) $5 \mathrm{~min},(\mathrm{~g}) 10 \mathrm{~min}$, (h) $15 \mathrm{~min}$, (i) $30 \mathrm{~min}$, and (j) $60 \mathrm{~min}$.

electrodeposition technique under varying current densities and deposition times. An analysis and discussion of PL properties of PSi/Co, aged for 60 days, are also presented.

\section{Experimental}

Porous silicon (PSi) sample or substrate was obtained by cutting a phosphorous doped, double-sided polished n-type Si wafer with $\left(\begin{array}{lll}1 & 0 & 0\end{array}\right)$ orientation and $1-10 \Omega \mathrm{cm}$ resistivity and carrying out an anodization procedure in HF solution (40\%)/Ethanol (99.8\%) (1:1) with backside illumination. The applied current density was selected as a constant $60 \mathrm{~mA} / \mathrm{cm}^{2}$ for $30 \mathrm{~min}$.

The cobalt deposition was carried out in dark with a two-electrode system at room temperature. The working and counter electrodes were a PSi substrate and platinum spiral, respectively. The solutions for electrodeposition consisted of an aqueous solution of $0.1 \mathrm{M}$ 

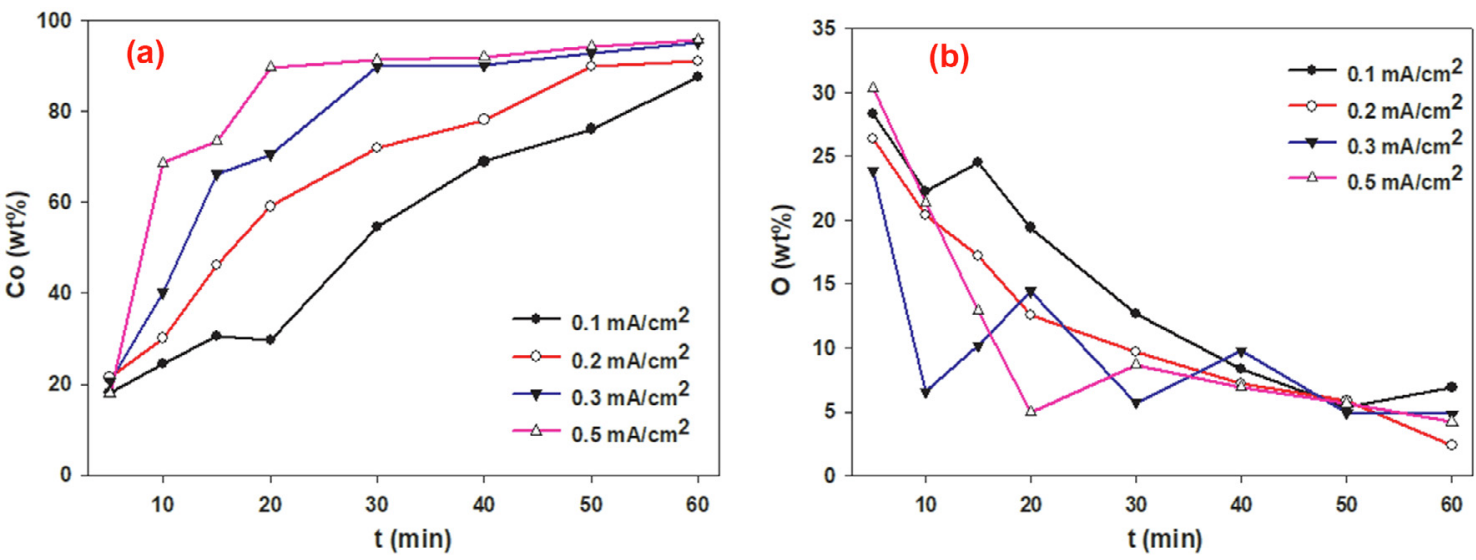

Fig. 4. Variation of cobalt and oxygen percentages in PSi/Co nanostructure obtained by EDAX analysis (as a function of deposition time).
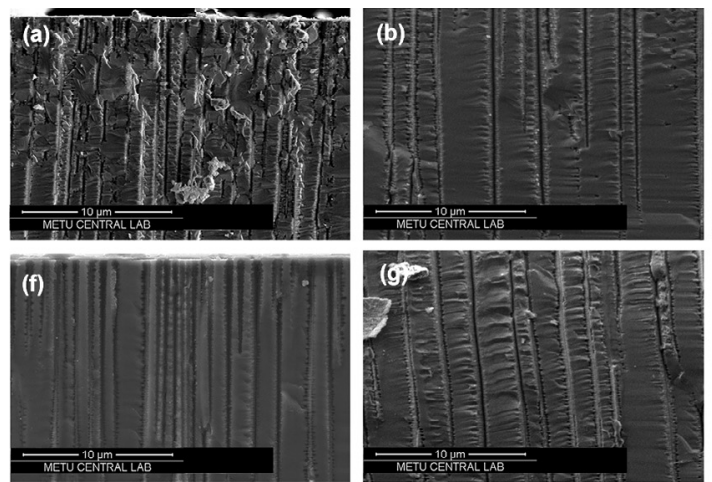
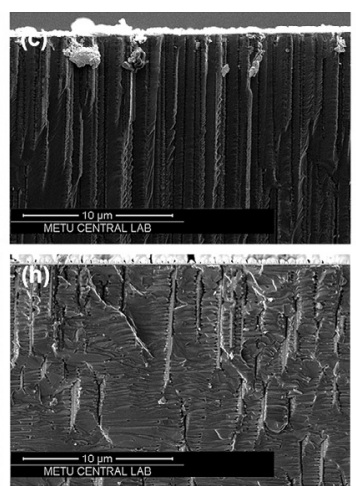
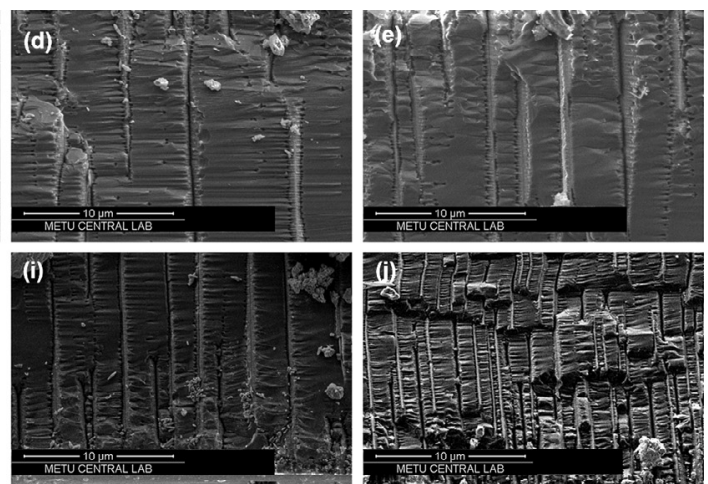

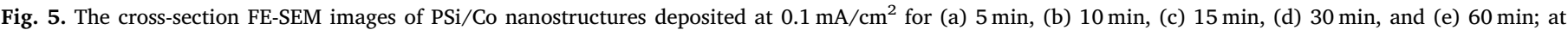
$0.2 \mathrm{~mA} / \mathrm{cm}^{2}$ for (f) $5 \mathrm{~min}$, (g) $10 \mathrm{~min}$, (h) $15 \mathrm{~min}$, (i) $30 \mathrm{~min}$, and (j) $60 \mathrm{~min}$.
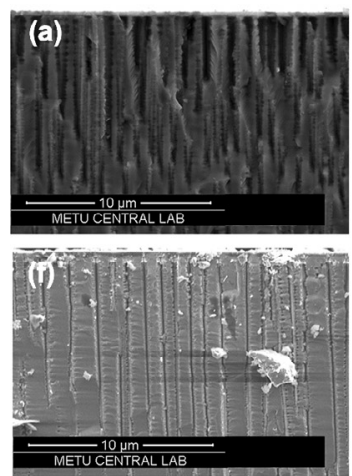
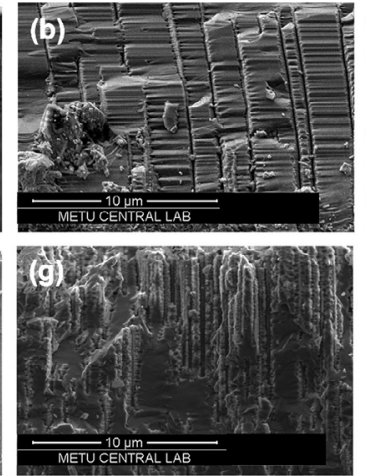
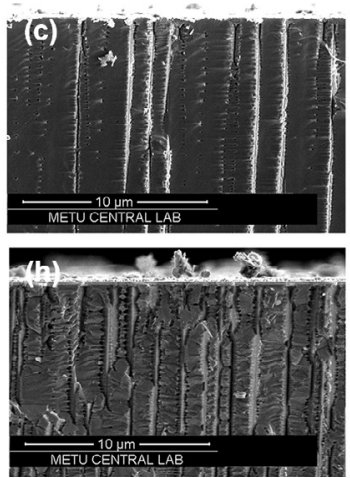
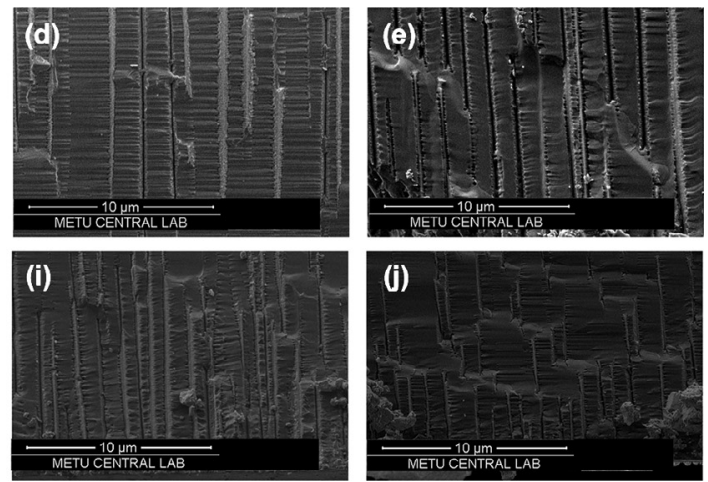

Fig. 6. The cross-section FE-SEM images of PSi/Co nanostructures deposited at $0.3 \mathrm{~mA} / \mathrm{cm}^{2}$ for (a) $5 \mathrm{~min}$, (b) $10 \mathrm{~min}$, (c) $15 \mathrm{~min}$, (d) $30 \mathrm{~min}$, and (e) $60 \mathrm{~min}$; at $0.5 \mathrm{~mA} / \mathrm{cm}^{2}$ for (f) $5 \mathrm{~min},(\mathrm{~g}) 10 \mathrm{~min}$, (h) $15 \mathrm{~min}$, (i) $30 \mathrm{~min}$, and (j) $60 \mathrm{~min}$.

$\mathrm{CoSO}_{4} \cdot 7 \mathrm{H}_{2} \mathrm{O}$ and $0.4 \mathrm{M} \mathrm{H}_{3} \mathrm{BO}_{3}(\mathrm{pH}=3.5)$. PSi/Co nanostructures were prepared in the current density range from 0.1 to $0.5 \mathrm{~mA} / \mathrm{cm}^{2}$ under stirring conditions $(\omega=500 \mathrm{rpm})$ after reversing the polarization direction. The electrodeposition durations were varied from 5 to $60 \mathrm{~min}$. After deposition, $\mathrm{PSi} / \mathrm{Co}$ samples were rinsed with distilled water.

Surface morphologies of PSi/Co nanostructures were investigated using a field emission scanning electron microscopy system (FE-SEM, QuantaFEG) attached with an energy-dispersive X-ray (EDAX) analyzer to measure the sample composition. X-ray diffraction (XRD) patterns of PSi/Co samples were obtained using a Philips X'Pert Pro X-Ray Diffraction system employing a CuKa radiation $(\lambda=0.15418 \mathrm{~nm})$. The Raman and PL spectra were recorded using an S\&I MonoVista Raman system employing an Ar-Ion laser with $488 \mathrm{~nm}$ wavelength emission, an Olympus BX51 upright microscope, a $750 \mathrm{~mm}$ focal length Princeton
Instruments monochromator with a proper set of 3 gratings, and a highresolution CCD camera array for a multichannel detection. The $488 \mathrm{~nm}$ line of Ar-ion laser with a maximum power of $120 \mathrm{~mW}$ was used for sample excitations. PL spectra of PSi/Co samples aged for 60 days in ambient air at room temperature were also recorded and compared with those obtained from the fresh PSi/Co samples.

\section{Results and discussion}

\subsection{SEM analyses}

SEM images of the cross section and the surface of a freshly prepared PSi substrate are presented in Fig. 1. The average pore diameter in this PSi sample, which has a high porosity, is about $850 \mathrm{~nm}$ obtained 

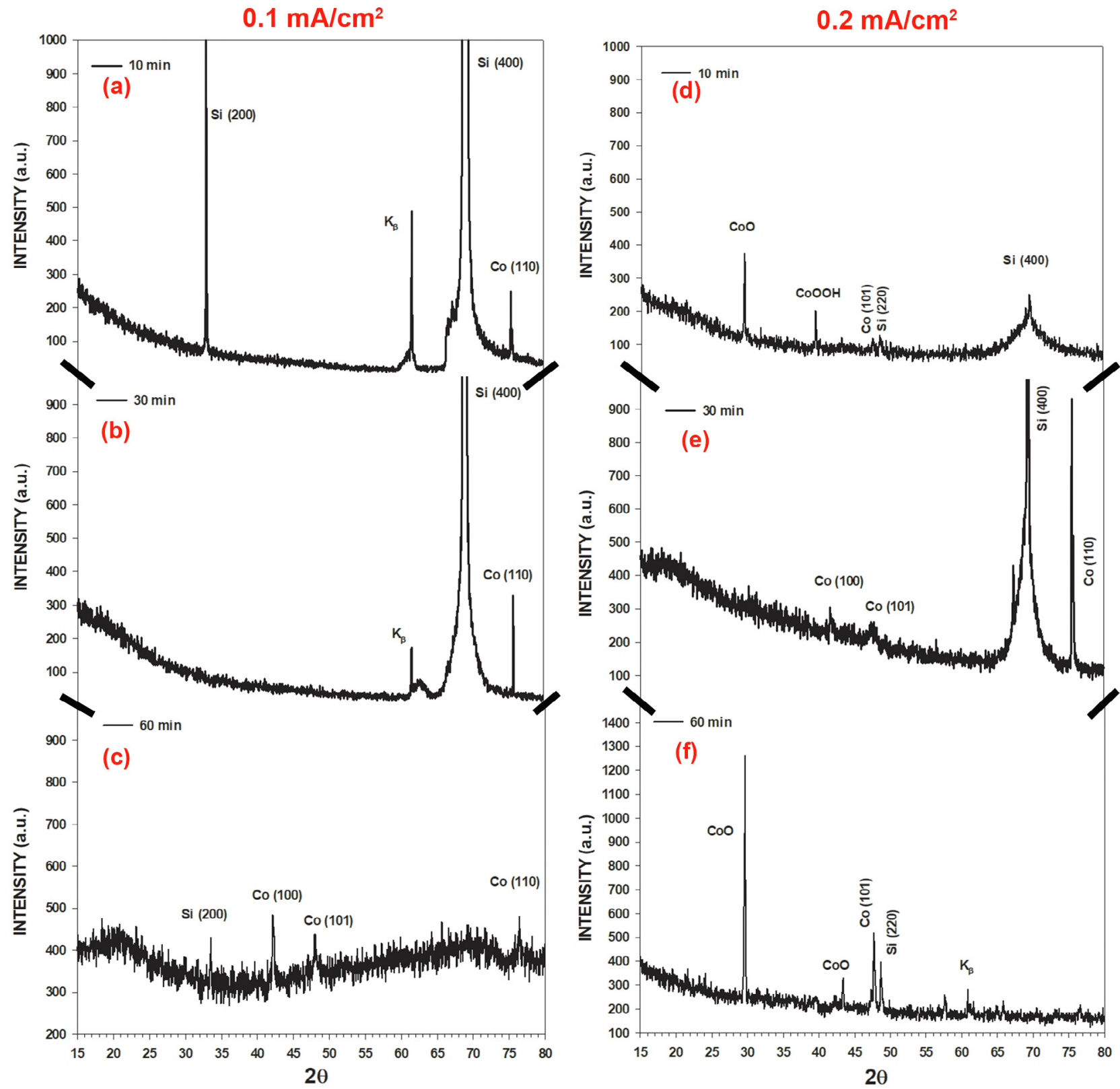

Fig. 7. XRD patterns of PSi/Co nanostructures deposited at $0.1 \mathrm{~mA} / \mathrm{cm}^{2}$ for (a) $10 \mathrm{~min}$, (b) $30 \mathrm{~min}$, and (c) $60 \mathrm{~min}$; at $0.2 \mathrm{~mA} / \mathrm{cm}^{2}$ for (d) $10 \mathrm{~min}$, (e) $30 \mathrm{~min}$, and (f) $60 \mathrm{~min}$.

from the SEM image. These pores can be classified as macropores [13]. The pores are straight, but pore walls have considerably rough morphologies. The average depth of the pores in PSi layer is about $50 \mu \mathrm{m}$ with a columnar structure perpendicular to the Si substrate surface. The pore channels are not interconnected with each other as seen from Fig. 1.

Figs. 2 and 3 show the influence of the current density and the deposition time on the morphologies of our PSi/Co samples. When the electrochemical reactions were performed at 0.1 and $0.2 \mathrm{~mA} / \mathrm{cm}^{2}$, Co nanoparticles agglomerated, and Co clusters were formed on the PSi surface (Fig. 2). Moreover, the nanoparticles in the Co cluster are significantly smaller than those in the other PSi/Co samples. At 0.3 and $0.5 \mathrm{~mA} / \mathrm{cm}^{2}$, as the deposition time was increased, the growth rate of Co nuclei was increased as well, leading to the formation of thin Co films composed of larger Co nanoparticles (Fig. 3). As can be seen in Figs. 2 and 3 , in the case of 5 min deposition time, the resulting Co nanoparticles are very small and nonuniform, whereas for $10 \mathrm{~min}$ deposition time, small cobalt clusters of spherical particles are observed on the surface of PSi. When the deposition time increases to $15 \mathrm{~min}$ and $30 \mathrm{~min}$, the resulting cobalt clusters of spherical particles become much denser and bigger. It is also found that the largest clusters of spherical Co nanoparticles are observed for $60 \mathrm{~min}$ and these clusters consist of Co nanoflakes [14]. As can be seen in the SEM images, the nanoflakes have formed along the radial direction expanding from the center to the edges of a nanoparticles cluster. Analysis of SEM images revealed that Co nanoparticles were accumulated as clusters on the Co nanoparticle clusters formed at the beginning of the deposition. From the SEM images, we can say that as the deposition time increases, Co nanoparticles grow faster on Co clusters than those on silicon, consequently, large Co clusters form a thick Co film layer on the surface [12]. This result has also been confirmed by EDAX analysis. According to Fig. 4, we can say that regardless of the applied current density, the amount of Co in PSi matrix increases while that of oxygen decreases with deposition time. The results of the SEM analyses suggest that size and 

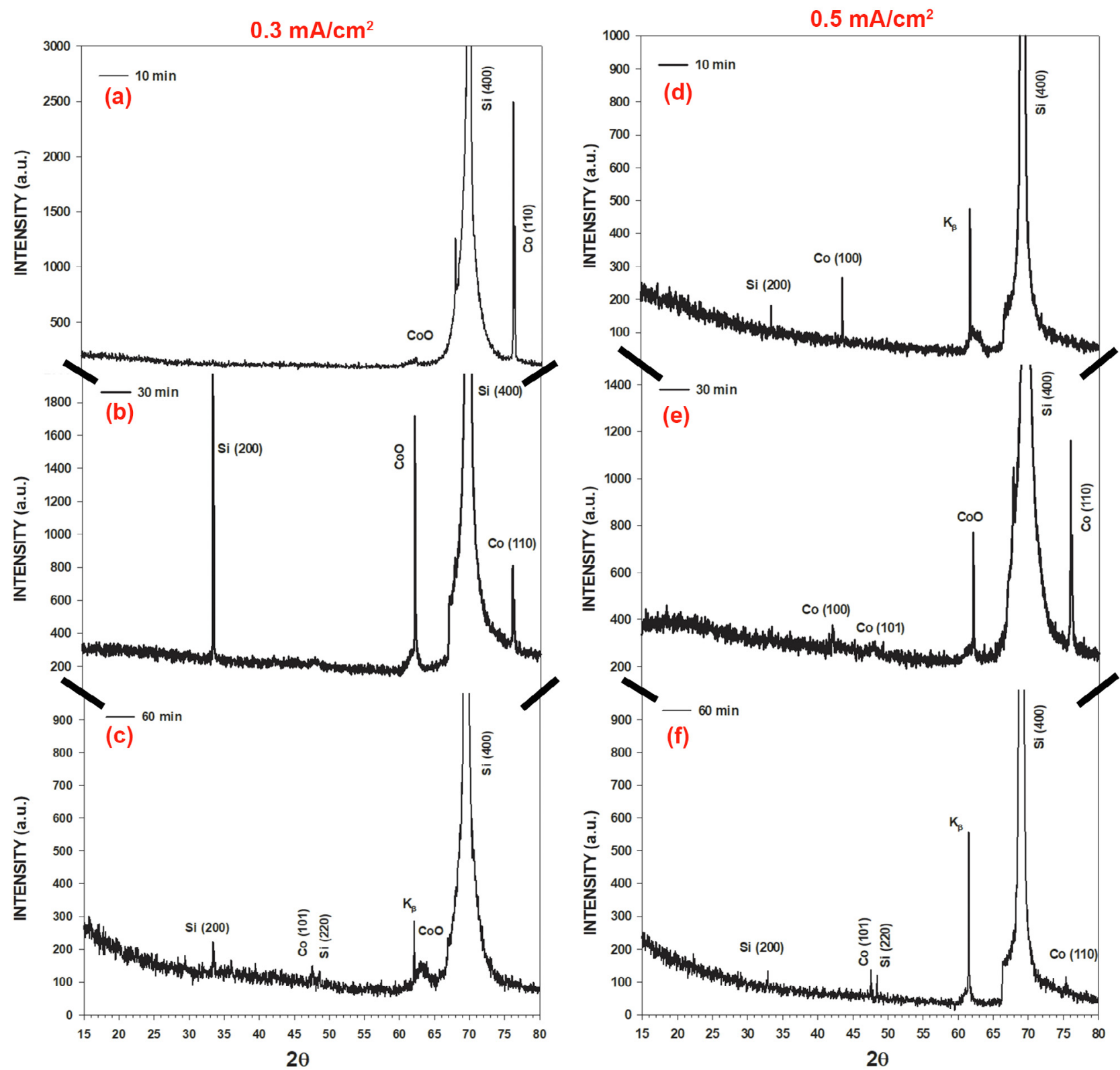

Fig. 8. XRD patterns of PSi/Co nanostructures deposited at $0.3 \mathrm{~mA} / \mathrm{cm}^{2}$ for (a) $10 \mathrm{~min}$, (b) $30 \mathrm{~min}$, and (c) $60 \mathrm{~min}$; at $0.5 \mathrm{~mA} / \mathrm{cm}^{2}$ for (d) $10 \mathrm{~min}$, (e) $30 \mathrm{~min}$, and (f) $60 \mathrm{~min}$.

thickness of Co nanostructures could be tuned by changing the deposition time and current density.

Figs. 5 and 6 show the cross-sectional SEM images of PSi/Co samples deposited under various conditions. It should be noted that some larger particles observed in the images may have fallen down during the cleavage from the surface of PSi/Co. We can see from the images that some pores are filled continuously from the bottom to the surface, but some are empty or partially filled. The latter case is due to the bottleneck effect [15], which means the closing of the pore opening before it is fully filled with the deposited metal. Fang et al. [15] and Fukami et al. [16] presented that very high current densities may lead to nuclei formation both the pore tip and the surface, whereas low current densities might produce nuclei formation only in some pores, and then inhomogeneous filling occurs. Thus, the applied current density must be carefully selected to avoid pore bottleneck effect. For uniformly filled pores, Co deposition occurs at the pore bottom and also entire pore wall seems to be covered with Co nanoparticles. The cross-sectional SEM analysis reveals that with increasing current densities and deposition times, the amount of Co deposits in and on the PSi matrix generally increase.

\subsection{XRD analyses}

The PSi/Co nanostructures were also characterized using X-ray diffractometry (XRD). It can be seen from Figs. 7 and 8 that the XRD spectra of the PSi/Co nanostructures prepared at 0.1 and $0.2 \mathrm{~mA} / \mathrm{cm}^{2}$ current densities vary with changing deposition times. As seen from Fig. 7 , as the deposition time increases, the $\mathrm{Si}\left(\begin{array}{ll}40 & 0\end{array}\right)$ peak intensity decreases slightly. This result indicates that the thickness of the Co layer increases with the increasing deposition time, as confirmed by SEM analysis. From the diffraction peaks of PSi/Co, such as those shown in Fig. 7(a-c), we can assign a hexagonal close packed (hcp) phase for Co nanostructures $[17,18]$. As shown in Fig. $7(\mathrm{~d}-\mathrm{f})$, the XRD spectra of $\mathrm{PSi} / \mathrm{Co}$ prepared at $0.2 \mathrm{~mA} / \mathrm{cm}^{2}$ have two weak peaks at 29 and $42.8^{\circ}$, corresponding to a cubic $\mathrm{CoO}$ structure [18]. Moreover, no appreciable preferential orientation of the PSi/Co samples is observed 

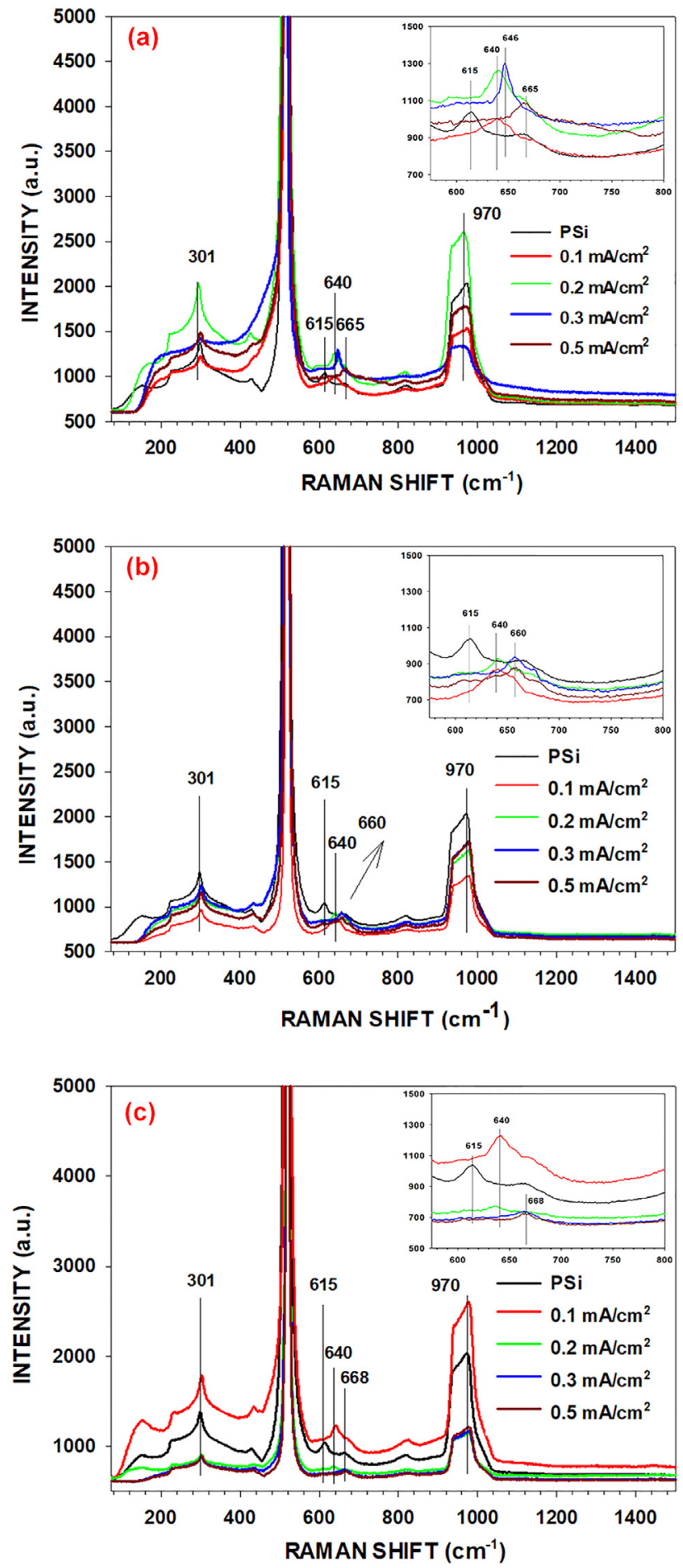

Fig. 9. Raman spectra of as-prepared PSi/Co nanostructures as function of current density, (a) $10 \mathrm{~min}$, (b) $30 \mathrm{~min}$, and (c) 60 min deposition times (Raman spectrum from an undoped reference PSi sample is also shown for comparison). The insets of Fig. 9 show the weak and broad peaks appearing at $575-800 \mathrm{~cm}^{-1}$.

in Fig. 7. Apart from the Co diffraction peaks, the Si $\left(\begin{array}{ll}4 & 0\end{array}\right)$ peak observed at $70^{\circ}$ is the main peak of the n-type Si $\left(\begin{array}{lll}1 & 0 & 0\end{array}\right)$ substrate. Furthermore, the peak observed at $61.7^{\circ}$ belongs to the $\mathrm{K}_{\beta}$ radiation diffracted from the Si (4 00 ) planes [19]. Similar diffraction patterns are obtained for the PSi/Co samples prepared with 0.3 and $0.5 \mathrm{~mA} / \mathrm{cm}^{2}$ current densities (Fig. 8). The analyses of the XRD spectra of the PSi/Co samples such those shown in Fig. 8 reveal an hcp-Co phase as inferred from the peak at $65^{\circ}$, which was assigned to the $(220)$ reflections from $\mathrm{CoO}$ [17]. In Fig. 8, the $\mathrm{Si}(400)$ reflections are more visible because of the low crystallinity of the $\mathrm{CoO}$ layer.

\subsection{Raman analyses}

Raman spectroscopy, which is a very sensitive technique to probe the local atomic vibrations along with non-local phonons (as well as electronic transitions and molecular rotations), is a suitable tool to characterize Co nanostructures on PSi. Raman spectra of the as-prepared PSi reference and PSi/Co nanostructures are given in Fig. 9. Five fundamental Raman bands of PSi are observed at the 301, 430, 515, $615,970 \mathrm{~cm}^{-1}$. Among these, $301 \mathrm{~cm}^{-1}$ and $515.5 \mathrm{~cm}^{-1}$ peaks are due to 2TA and TO phonon modes of Si [13]. The peak around $430 \mathrm{~cm}^{-1}$ observed in the Raman spectra of PSi and PSi/Co samples is related to a local Si phonon mode due to a compositional disorder and localization in the PSi matrix [20]. The peak at $615 \mathrm{~cm}^{-1}$ is due to "wagging" vibrations of $\mathrm{Si}-\mathrm{H}$ bonds (TO + TA) [21]. The broad and intense band spanning the region from 900 to $1000 \mathrm{~cm}^{-1}$ is due to stretching modes of $\mathrm{Si}-\mathrm{OH}$ bonds on the surface [13]. We did not observe a $480 \mathrm{~cm}^{-1}$ peak in the Raman spectra of all samples which indicates that there is no amorphous $\mathrm{Si}$ in the structure [22]. As seen in Fig. 9, after the electrodeposition process, a new peak appears in the range of $640-665 \mathrm{~cm}^{-1}$ based on the current density, instead of the peak of the $\mathrm{Si}-\mathrm{H}$ bonds at $615 \mathrm{~cm}^{-1}$ in the Raman spectra of the PSi/Co samples. As demonstrated by many authors [6,23-25], metal or metal-oxide bonds occur between $620 \mathrm{~cm}^{-1}$ and $700 \mathrm{~cm}^{-1}$. Therefore, the new peak can be attributed to vibrations modes of more stable Si-Co or Si-O-Co formations after the breaking of weak $\mathrm{Si}-\mathrm{H}$ bonds present in the PSi. Moreover, as the current density was increased, the new Raman peak of $\mathrm{PSi} / \mathrm{Co}$ sample, prepared at $10 \mathrm{~min}$ of deposition time, shifted to higher wavenumber (from $640 \mathrm{~cm}^{-1}$ to $665 \mathrm{~cm}^{-1}$ ). In a similar manner, for 30 and $60 \mathrm{~min}$ of deposition times, the Raman peak of Si-Co or Si-O-Co shifted towards higher wavenumber (from $640 \mathrm{~cm}^{-1}$ to $660 \mathrm{~cm}^{-1}$ and to $668 \mathrm{~cm}^{-1}$, respectively) with increasing current density, as seen in Fig. 9. The shift of this band towards higher wavenumber can be attributed to both increased particle size and residual stress in PSi/Co matrix $[25,26]$.

Raman results have shown that the Si TO phonon peak of the PSi/Co samples with 0.2 and $0.3 \mathrm{~mA} / \mathrm{cm}^{2}$ current densities for $10 \mathrm{~min}$ are more asymmetric in shape compared to that of the reference PSi sample. From Fig. 9 and Table 1, we have found that the Raman peak position of the PSi/Co samples with $0.3 \mathrm{~mA} / \mathrm{cm}^{2}$ current density for $10 \mathrm{~min}$ shifts from 520 and $517 \mathrm{~cm}^{-1}$ down to $514.5 \mathrm{~cm}^{-1}$, and that the FWHM increases from 2.4 and $6.0 \mathrm{~cm}^{-1}$ to $8.5 \mathrm{~cm}^{-1}$ relative to c-Si and reference PSi sample, respectively. These observed changes in Raman spectra of PSi/Co samples could be explained by the quantum confinement effect (QCE) considering that the size of the Si nanocrystallites in the PSi/Co samples is under $5 \mathrm{~nm}$, leading to the confinement of optical phonons in Si nanocrystals among the pore walls [4,27]. On the other hand, for 30- and 60-min samples, the shape of the main TO peak of $\mathrm{Si}$ became more symmetric while its full width at half maximum (FWHM) decreased indicating no quantum confinement effect occurred in them. We have been also calculated size of the Si nanocrystallites of PSi/Co samples using Microcrystal Model based on the QCE [13]. The calculated size of nanocrystallites has been summarized in Table 1. As can be seen in Table 1, the other calculated spectral parameters are the coefficient of broadening $\left(\mathrm{C}_{\mathrm{b}}\right)\left(\mathrm{FWHM}_{\mathrm{PSi}} / \mathrm{FWHM}_{\mathrm{c}-\mathrm{Si}}\right)$ and the asymmetric coefficient $\left(\mathrm{C}_{\mathrm{a}}\right)$ (LWHM/RWHM, where LWHM and RWHM are the left width at half maximum and the right width at half maximum from the central peak position, respectively). We have found that as increasing the deposition time, the FWHM of the main TO peak of $\mathrm{Si}$, the coefficient of broadening $\left(\mathrm{C}_{\mathrm{b}}\right)$ and asymmetric coefficient $\left(\mathrm{C}_{\mathrm{a}}\right)$ of $\mathrm{PSi} / \mathrm{Co}$ samples decrease, while nanocrystallite size of PSi/Co samples increases. It should be important to note that as presented by many authors $[25,28]$, if the surface $\mathrm{Si}$ atoms bond to oxygen ions, the 
Table 1

Spectral parameters determined from Raman analysis and calculated crystallite size using microcrystal model (MCM) based on QCE.

\begin{tabular}{|c|c|c|c|c|c|c|c|}
\hline Sample & $\begin{array}{l}\text { Deposition Time } \\
\text { (min) }\end{array}$ & $\begin{array}{l}\text { Current Density } \\
\left(\mathrm{mA} / \mathrm{cm}^{2}\right)\end{array}$ & $\begin{array}{l}\text { Raman Frequency of Si } \\
\text { TO phonon peak }\left(\mathrm{cm}^{-1}\right)\end{array}$ & $\begin{array}{l}\text { FWHM of Si TO } \\
\text { phonon peak } \\
\left(\mathrm{cm}^{-1}\right)\end{array}$ & $\begin{array}{l}\text { Coefficient of } \\
\text { Broadening }\left(\mathrm{C}_{\mathrm{b}}\right)\end{array}$ & $\begin{array}{l}\text { Asymmetric } \\
\text { Coefficient }\left(\mathrm{C}_{\mathrm{a}}\right)\end{array}$ & $\begin{array}{l}\text { Size of the } \mathrm{Si} \\
\text { nanocrystallites }(\mathrm{nm})\end{array}$ \\
\hline c-Si & - & - & 520.0 & 2.4 & 1.00 & 1.00 & - \\
\hline Reference PSi & - & - & 517.0 & 6.0 & 2.50 & 1.25 & 5.4 \\
\hline \multirow[t]{12}{*}{ PSi/Co } & 10 & 0.1 & 517.0 & 7.4 & 3.08 & 1.33 & 5.4 \\
\hline & & 0.2 & 515.8 & 8.0 & 3.33 & 1.40 & 4.5 \\
\hline & & 0.3 & 514.5 & 8.5 & 3.54 & 1.43 & 4.0 \\
\hline & & 0.5 & 517.2 & 7.0 & 2.91 & 1.26 & 5.6 \\
\hline & 30 & 0.1 & 519.6 & 6.0 & 2.50 & 1.16 & 14.7 \\
\hline & & 0.2 & 518.6 & 6.0 & 2.50 & 1.21 & 7.9 \\
\hline & & 0.3 & 518.6 & 5.6 & 2.33 & 1.17 & 7.9 \\
\hline & & 0.5 & 519.9 & 5.5 & 2.29 & 1.06 & 29.5 \\
\hline & 60 & 0.1 & 519.6 & 6.0 & 2.50 & 1.10 & 14.7 \\
\hline & & 0.2 & 519.9 & 6.0 & 2.50 & 1.13 & 29.5 \\
\hline & & 0.3 & 519.9 & 5.0 & 2.08 & 1.03 & 29.5 \\
\hline & & 0.5 & 519.9 & 5.5 & 2.29 & 1.06 & 29.5 \\
\hline
\end{tabular}
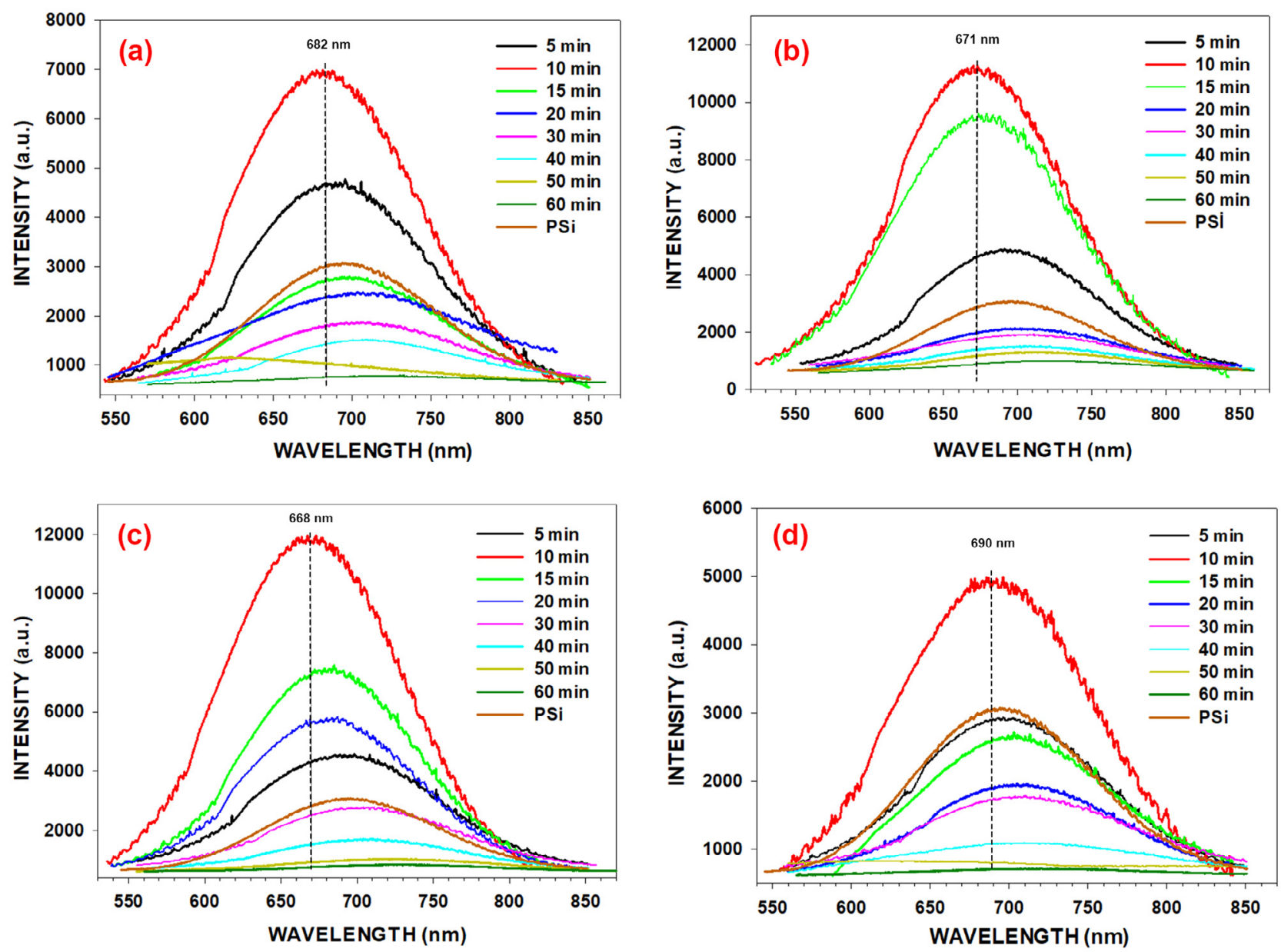

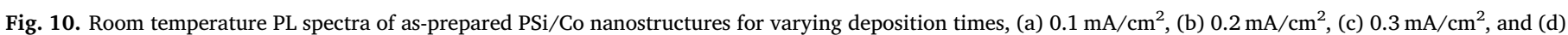
$0.5 \mathrm{~mA} / \mathrm{cm}^{2}$, (The PL spectrum from an undoped reference PSi sample is also shown for comparison).

electrostatic potential of electrons in $\mathrm{Si}$ increases due to the negative charge of the oxygen, and this causes reducing the size of Si nanocrystallites. Thus, obtained results from Raman analysis can be attributed increasing cobalt deposition and decreasing the oxygen level on PSi surface with increasing deposition time, as confirmed by SEM and EDAX analyses. We can conclude that although a major contribution of the Raman scattering of PSi/Co samples belongs to the Si nanocrystallites (less than $5 \mathrm{~nm}$ ) of PSi/Co, Co nanostructures deposited on PSi have a significant influence on Raman spectra of PSi/Co samples.

\subsection{Photoluminescence analyses}

Fig. 10 and Table 2 show the effects of deposition time and current density on the PL properties of PSi/Co nanostructures. As already mentioned, SEM analyses have revealed that the density of cobalt is low, and the growth of cobalt cluster randomly occurs on the PSi 
Table 2

Effect of the current density and deposition time on PL characteristics of PSi/Co nanostructures.

\begin{tabular}{|c|c|c|c|c|c|c|c|}
\hline Sample & $\begin{array}{l}\text { Current Density } \\
\left(\mathrm{mA} / \mathrm{cm}^{2}\right)\end{array}$ & $\begin{array}{l}\text { Deposition Time } \\
\text { (min) }\end{array}$ & $\begin{array}{l}\text { PL intensity (a.u.) } \\
\text { (as-prepared) }\end{array}$ & $\begin{array}{l}\text { PL peak maximum (nm/ } \\
\text { eV) }( \pm 1 \mathrm{~nm}) \text { (as- } \\
\text { prepared) }\end{array}$ & $\begin{array}{l}\text { PL intensity (a.u.) } \\
\text { (after } 60 \text { days) }\end{array}$ & $\begin{array}{l}\text { PL peak maximum (nm/ } \\
\text { eV) }( \pm 1 \mathrm{~nm}) \text { (after } \\
60 \text { days) }\end{array}$ & $\begin{array}{l}\text { Degradation rate of PL } \\
\text { intensity }(\%)\end{array}$ \\
\hline Reference PSi & & & 3050 & $692 / 1.79$ & 2378 & $689 / 1.80$ & 22.03 \\
\hline \multirow[t]{16}{*}{$\mathrm{PSi} / \mathrm{Co}$} & 0.1 & 5 & 4710 & $690 / 1.80$ & 3664 & $691 / 1.79$ & 22.20 \\
\hline & & 10 & 6950 & $682 / 1.82$ & 6167 & $680 / 1.82$ & 11.26 \\
\hline & & 15 & 2604 & $700 / 1.77$ & 2210 & $702 / 1.77$ & 15.13 \\
\hline & & 20 & 2390 & $705 / 1.76$ & 2065 & $703 / 1.76$ & 13.59 \\
\hline & 0.2 & 5 & 4965 & $691 / 1.79$ & 3956 & $692 / 1.79$ & 20.32 \\
\hline & & 10 & 11,429 & $671 / 1.85$ & 10,800 & $671 / 1.85$ & 5.50 \\
\hline & & 15 & 9951 & $674 / 1.84$ & 9410 & $675 / 1.84$ & 5.43 \\
\hline & & 20 & 2210 & $704 / 1.76$ & 2082 & $706 / 1.76$ & 5.79 \\
\hline & 0.3 & 5 & 4500 & $692 / 1.79$ & 3577 & $695 / 1.78$ & 20.51 \\
\hline & & 10 & 11,861 & $668 / 1.86$ & 11,220 & $669 / 1.85$ & 5.40 \\
\hline & & 15 & 7452 & $680 / 1.82$ & 7048 & $679 / 1.82$ & 5.42 \\
\hline & & 20 & 5816 & $682 / 1.82$ & 5518 & $687 / 1.80$ & 5.12 \\
\hline & 0.5 & 5 & 2795 & $697 / 1.78$ & 2125 & $699 / 1.77$ & 23.97 \\
\hline & & 10 & 4918 & $690 / 1.80$ & 4708 & $691 / 1.79$ & 4.27 \\
\hline & & 15 & 2620 & $704 / 1.76$ & 2510 & $701 / 1.77$ & 4.19 \\
\hline & & 20 & 1934 & $706 / 1.76$ & 1847 & $709 / 1.75$ & 4.49 \\
\hline
\end{tabular}
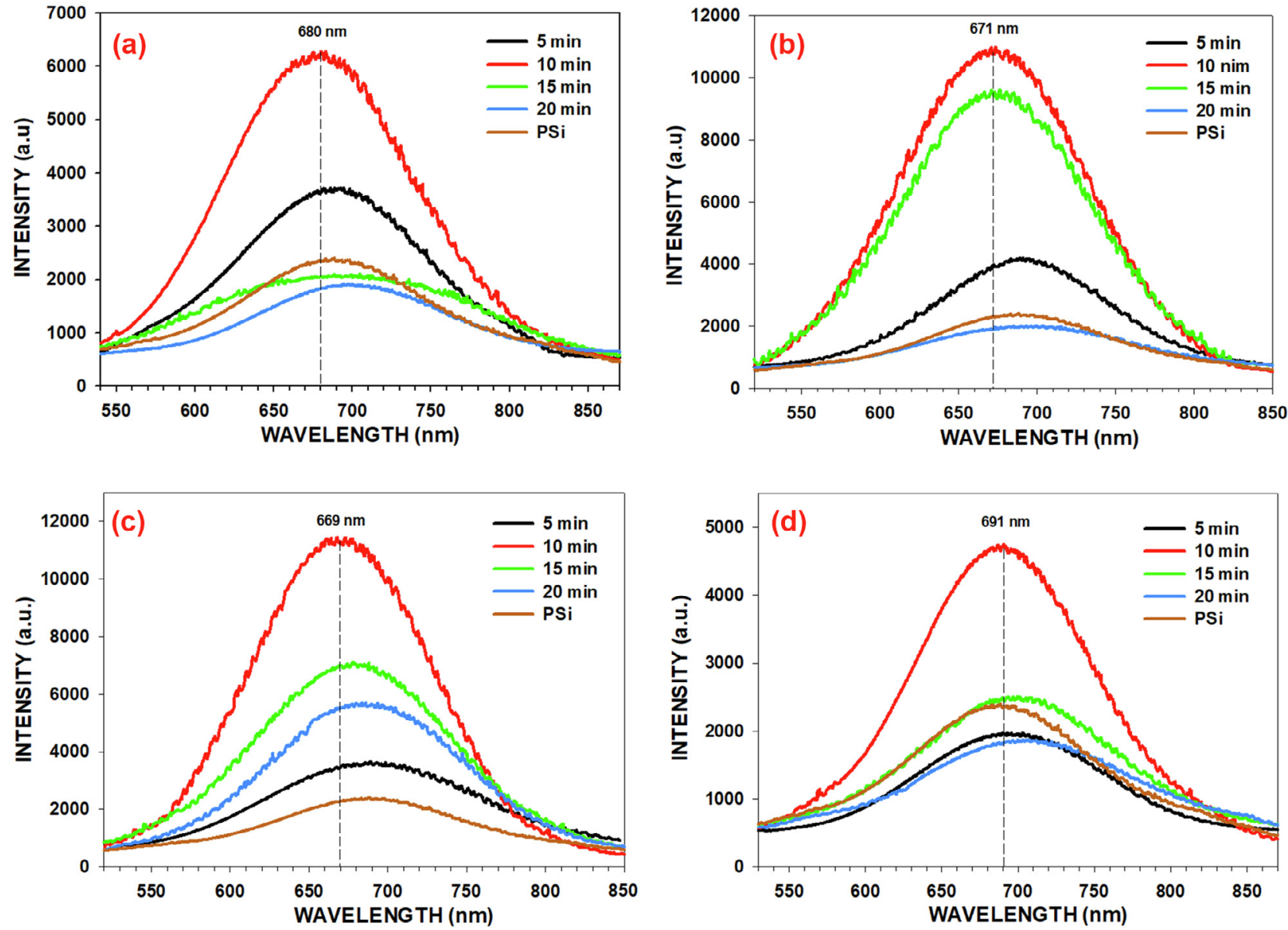

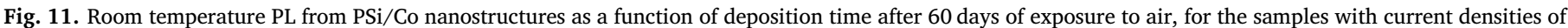
(a) $0.1 \mathrm{~mA} / \mathrm{cm}^{2}$, (b) $0.2 \mathrm{~mA} / \mathrm{cm}^{2}$, (c) $0.3 \mathrm{~mA} / \mathrm{cm}^{2}$, and (d) $0.5 \mathrm{~mA} / \mathrm{cm}^{2}$, (The PL spectrum from an undoped reference PSi sample is also shown for comparison).

surface for short deposition times $\left(t_{s}\right)$ at all current densities. However, the effect of cobalt deposition on PL intensity of these samples is significant and the PL intensities of these samples are slightly higher than that of the reference PSi sample. These results indicate that the cobalt/ cobalt oxide nanoparticles deposited in the PSi matrix for 10 and 15 min create new radiative recombination centers and changes the surface electronics states, resulting in enhanced photoluminescence intensities for the PSi/Co samples by a factor of 4 as compared to that of the PSi sample. Among all our PSi/Co samples, the highest PL intensities are from those with $10 \mathrm{~min}$ at 0.2 and $0.3 \mathrm{~mA} / \mathrm{cm}^{2}$ current densities. PL enhancement in these PSi/Co samples can be explained in terms of quantum confinement effect (Table 2). The results of Raman and PL analyses show that with reducing size of the Si nanocrystallites, the quantum confinement effect is enhanced, hence PL intensity 
increases. However, as can be seen from Fig. 10 and Table 2 the PL intensity of PSi/Co samples prepared in short deposition times decreases with increasing current density due to the excessive Co deposition. It is also observed that for all current densities, the PL peak position of the PSi/Co samples, prepared at $5 \mathrm{~min}$, is close to that of the reference PSi. When the deposition time increases to $10 \mathrm{~min}$, the PL peak is blue-shifted (up to $24 \mathrm{~nm}$ in wavelength), but, with increasing deposition time from $10 \mathrm{~min}$ to $60 \mathrm{~min}$, the PL peak position is consistently red-shifted (up to $14 \mathrm{~nm}$ in wavelength), compared to that of the reference PSi. The blue shift of the PL peak position, i.e. the increase in the band gap of the PSi/Co samples, could be resulted from the oxygen atoms forming cobalt oxide compounds at the PSi/Co interface for short deposition times [28-30]. On the other hand, observed redshift in the PL spectra of PSi/Co samples with increasing deposition time, has arisen from the clustering Co nanoparticle on the surface which causes an increase in the number of non-radiative centers $[31,32]$. The results of our PL analyses show that the origin of the effective room temperature PL in PSi/Co nanostructures is attributed to some different physical mechanisms, such as surface effects, in addition to the quantum confinement effect. It should be also noted that the results of the PL analyses are in good agreement with those of SEM, XRD and Raman analyses.

As can be seen in Fig. 10, for long deposition times $\left(t_{1}>20 \mathrm{~min}\right)$, the PSi/Co samples show a significant decrease in the PL intensities with a shift towards longer wavelengths (up to $14 \mathrm{~nm}$ in wavelength, red shift), due to the increased cobalt densities and particle sizes on/in the PSi surface. This reduction in the PL intensities means that the number of non-radiative centers increased with the increasing cobalt density on the PSi surface causing a reduction in the probability of electron-hole recombination process. This reduction of PL intensities with increasing Co densities on the PSi surface is called the auto-extinction phenomenon $[4,6,33,34]$. We can conclude that both deposition time and current density affect the PL intensity of the PSi/Co nanostructure, but the effect of deposition time is more pronounced.

Fig. 11 shows the PL spectra of the PSi reference sample and PSi/Co samples, prepared with different deposition times and current densities, exposed to air for 60 days at room temperature. It is seen from Fig. 11 and Table 2 that, after 60 days of exposure to the air, the PL intensity of the undoped PSi reference sample degraded dramatically, but the PL intensities of the PSi/Co samples decayed more slowly depending on the deposition time and current density. As previously mentioned in SEM analysis, for 5 min deposition time, small Co clusters of spherical particles formed on the surface of the PSi/Co samples. Since the cluster consisting of Co nanoparticles cannot passivate the surface to the desired extent, degradation of the PL intensity is very high (Fig. 11 and Table 2). This result indicates that PSi matrix contains a considerable number of Si-dangling bonds, resulting in the degradation of the PL intensity. It is well known that the poor PL characteristics of PSi nanostructures are due to $\mathrm{Si}-\mathrm{H}$ bonds on their surface, which can easily be broken by oxygen [1]. We can say that after exposure to air, the $\mathrm{Si}-\mathrm{H}$ bonds in PSi matrix turn into Si-dangling bonds which are proved to be non-luminescent [1]. For 10-20 min deposition times, the amount of cobalt in PSi matrix increases and passivates most of the Si-dangling bonds, as a result, the PL characteristics are stabilized. PL analyses reveal that with increasing current density (from $0.1 \mathrm{~mA} / \mathrm{cm}^{2}$ to $0.5 \mathrm{~mA} / \mathrm{cm}^{2}$ ) and deposition time (from $5 \mathrm{~min}$ to $20 \mathrm{~min}$ ), degradation of the PL intensity decreases due to Co atoms replaced with the $\mathrm{H}$ atoms in $\mathrm{Si}-\mathrm{H}$ bonds and formed more stable Si-Co bonds which act as new radiative recombination centers in the PSi matrix. Consequently, the presented results reveal that the PSi/Co sample with easily controllable structural and optical properties, is a good candidate for the potential applications in optoelectronic and sensor devices.

\section{Conclusion}

In this study, we have synthesized cobalt nanostructures on a PSi matrix with varying deposition times and current densities using an electrochemical deposition method. Then, we studied the effects of deposition time and current density on the morphological and photoluminescence characteristics of the PSi/Co nanostructures by SEM micrography and XRD, Raman and photoluminescence spectroscopies. SEM analysis revealed that the Co nanoparticles have spherical shapes for shorter deposition times $\left(t_{s} \leq 20 \mathrm{~min}\right)$, while the nano-flake Co structure has formed for the longer times. EDAX, XRD, and Raman analyses confirmed the presence of $\mathrm{Co}$ in the PSi matrix. Photoluminescence analyses revealed that at short deposition times $\left(\mathrm{t}_{\mathrm{s}} \leq 20 \mathrm{~min}\right.$ ), the PL intensities from PSi/Co samples increased by up to a factor of 4 compared to that from the PSi sample, but, it decreased and quenched for the samples at longer deposition times $\left(t_{1}>20 \mathrm{~min}\right)$. The decrease in PL intensity can be ascribed to the enhanced non-radiative recombination process, with increasing cobalt density on the PSi surface. The enhancement of PL signal from PSi/Co samples at $t_{s}$, with respect to PSi reference sample, was attributed to a combination of two causes, that are; firstly, a quantum confinement of the optical phonons of $\mathrm{Si}$ nanocrystallites in the pore walls of PSi matrix, and secondly, surface effects, such as $\mathrm{Si}-\mathrm{Co}-\mathrm{O}$ bonds, which generate new radiative recombination centers. The improved PL emission from a PSi/Co nanostructure was stable even after PSi/Co samples were exposed to air for 60 days. The presented results indicate that Co nanostructures are ideally suited for the passivation of the PSi surface and tailoring the properties of PSi. We may conclude that PSi/Co samples with remarkable PL properties can make a significant contribution to the LED applications and to the literature.

\section{Acknowledgments}

This work was supported by the Ege University, Research Project Foundation (Project no.: 2013FEN058).

\section{Availability of data and materials}

The datasets supporting the conclusions of this article are included within the article and its additional files.

\section{References}

[1] A.G. Cullis, L.T. Canham, P.D.J. Calcott, The structural and luminescence properties of porous silicon, Appl. Phys. Rev. 82 (1997) 909-965.

[2] M.A. Tischler, R.T. Collins, J.H. Stathis, J.C. Tsang, Luminescence degradation in porous silicon, Appl. Phys. Lett. 60 (1992) 639-641, https://doi.org/10.1063/1. 106578.

[3] H.S. Mavi, B.G. Rasheed, A.K. Shukla, R.K. Soni, Photoluminescence and Raman study of iron-passivated porous silicon, Mater. Sci. Eng., B B97 (2003) 239 http:// link.aip.org/link/?APPLAB/93/123102/1.

[4] M. Rahmani, A. Moadhen, M.A. Zaïbi, H. Elhouichet, M. Oueslati, Photoluminescence enhancement and stabilisation of porous silicon passivated by iron, J. Lumin. 128 (2008) 1763-1766, https://doi.org/10.1016/j.jlumin.2008.04. iron,

[5] P. Granitzer, K. Rumpf, P. Pölt, S. Šimić, H. Krenn, Formation of self-assembled metal/silicon nanocomposites, Phys. Status Solidi Appl. Mater. Sci. 205 (2008) 1443-1446, https://doi.org/10.1002/pssa.200778114.

[6] M.B. Bouzourâa, M. Rahmani, M.A. Zaïbi, N. Lorrain, L. Hajji, M. Oueslati, Optical study of annealed cobalt-porous silicon nanocomposites, J. Lumin. 143 (2013) 521-525, https://doi.org/10.1016/j.jlumin.2013.05.050.

[7] S. Amdouni, M. Rahmani, M.A. Zaïbi, M. Oueslati, Enhancement of porous silicon photoluminescence by electroless deposition of nickel, J. Lumin. 157 (2015) 93-97, https://doi.org/10.1016/j.jlumin.2014.08.041.

[8] F.G. Zeng, C.C. Zhu, X.N. Fu, W.W. Wang, Z.M. Zhao, Preparation of Co-passivated porous silicon by stain etching, Mater. Chem. Phys. 90 (2005) 310-314, https://doi. org/10.1016/j.matchemphys.2004.06.005.

[9] A. Muñoz-Noval, V. Sánchez-Vaquero, V. Torres-Costa, D. Gallach, V. Ferro-Llanos, J. Javier Serrano, M. Manso-Silván, J.P. García-Ruiz, F. del Pozo, R.J. MartínPalma, Hybrid luminescent/magnetic nanostructured porous silicon particles for biomedical applications, J. Biomed. Opt. 16 (2011) 025002, https://doi.org/10. $1117 / 1.3533321$

[10] Á. Muñoz-Noval, D. Gallach, M.Á. García, V. Ferro-llanos, P. Herrero, K. Fukami, Y.H. Ogata, V. Torres-costa, R.J. Martín-palma, A. Ciment-font, Characterization of hybrid cobalt-porous silicon systems: protective effect of the matrix in the metal oxidation, Nanoscale Res. Lett. 7 (2012) 1-6, https://doi.org/10.1186/1556-276X- 
7-495.

[11] K. Rumpf, P. Granitzer, M. Reissner, P. Poelt, M. Albu, Investigation of Ni and Co deposition into porous silicon and the influence of the electrochemical parameters on the physical properties, ECS Trans. 41 (2012) 59-64, https://doi.org/10.1149/1. 4718391.

[12] M.R. Khelladi, L. Mentar, A. Azizi, F. Kadirgan, G. Schmerber, A. Dinia, Nucleation, growth and properties of Co nanostructures electrodeposited on n-Si(1 11 ), Appl. Surf. Sci. 258 (2012) 3907-3912, https://doi.org/10.1016/j.apsusc.2011.12.060.

[13] A. Cetinel, N. Artunc, G. Sahin, E. Tarhan, Influence of applied current density on the nanostructural and light emitting properties of n-type porous silicon, Int. J. Mod. Phys. B 29 (2015) 1550093, https://doi.org/10.1142/S0217979215500939.

[14] F. Liu, B. Zhang, H. Su, H. Zhang, L. Zhang, W. Yang, Controllable synthesis of selfassembly $\mathrm{Co}_{3} \mathrm{O}_{4}$ nanoflake microspheres for electrochemical performance, Nanotechnology 27 (2016) 1-8, https://doi.org/10.1088/0957-4484/27/35/ 355603.

[15] C. Fang, E. Foca, S. Xu, J. Carstensen, H. Föll, Deep silicon macropores filled with copper by electrodeposition, J. Electrochem. Soc. 154 (2007) D45, https://doi.org/ 10.1149/1.2393090.

[16] K. Fukami, K. Kobayashi, T. Matsumoto, Y.L. Kawamura, T. Sakka, Y.H. Ogata, Electrodeposition of noble metals into ordered macropores in p-type silicon, J. Electrochem. Soc. 155 (2008) D443, https://doi.org/10.1149/1.2898714.

[17] D. Barreca, C. Massignan, S. Daolio, M. Fabrizio, C. Piccirillo, L. Armelao, E. Tondello, Composition and microstructure of cobalt oxide thin films obtained from a novel cobalt(II) precursor by chemical vapor deposition, Chem. Mater. 13 (2001) 588-593, https://doi.org/10.1021/cm001041x.

[18] N. Deo, M.F. Bain, J.H. Montgomery, H.S. Gamble, Study of magnetic properties of thin cobalt films deposited by chemical vapour deposition, J. Mater. Sci.: Mater. Electron. 6 (2005) 387-392.

[19] G. Utlu, N. Artunç, S. Budak, S. Tari, Structural and electrical characterization of the nickel silicide films formed at $850{ }^{\circ} \mathrm{C}$ by rapid thermal annealing of the $\mathrm{Ni} / \mathrm{Si}\left(\begin{array}{ll}1 & 0\end{array}\right)$ films, Appl. Surf. Sci. 256 (2010) 5069-5075, https://doi.org/10.1016/j.apsusc. 2010.03.062.

[20] K. Gao, S. Prucnal, A. Mücklich, W. Skorupa, S. Zhou, Fabrication of $\mathrm{Si}_{1-\mathrm{x}} \mathrm{Ge}_{\mathrm{x}}$ alloy on silicon by Ge-ION-implantation and short-time-annealing, Acta Phys. Pol. A 123 (2013) 858-861, https://doi.org/10.12693/APhysPolA.123.858.

[21] H. Yang, D.G. Cahill, X. Liu, J.L. Feldman, R.S. Crandall, Anomalously high thermal conductivity of amorphous $\mathrm{Si}$ deposited by hot-wire chemical vapor deposition, Phys. Rev. B (2010) 1-7, https://doi.org/10.1103/PhysRevB.81.104203.

[22] M.H. Brodsky, M. Cardona, J.J. Cuomo, Infrared and Raman spectra of the siliconhydrogen bonds in amorphous silicon prepared by glow discharge and sputtering,
Phys. Rev. B 16 (1977) 3556-3571, https://doi.org/10.1103/PhysRevB.16.3556.

[23] C.W. Tang, C. Bin Wang, S.H. Chien, Characterization of cobalt oxides studied by FT-IR, Raman, TPR and TG-MS, Thermochim. Acta 473 (2008) 68-73, https://doi. org $/ 10.1016 /$ j.tca.2008.04.015.

[24] F.M. Liu, J.H. Ye, B. Ren, Z.L. Yang, Y.Y. Liao, A. See, L. Chan, Z.Q. Tian, Raman spectroscopic studies of the formation processes of cobalt silicide thin films, Thin Solid Films 471 (2005) 257-263, https://doi.org/10.1016/j.tsf.2004.06.111.

[25] P. Chandramohan, M.P. Srinivasan, S. Velmurugan, S.V. Narasimhan, Cation distribution and particle size effect on Raman spectrum of $\mathrm{CoFe}_{2} \mathrm{O}_{4}$, J. Solid State Chem. 184 (2011) 89-96, https://doi.org/10.1016/j.jssc.2010.10.019.

[26] Q. Li, W. Qiu, H. Tan, J. Guo, Y. Kang, Micro-Raman spectroscopy stress measurement method for porous silicon film, Opt. Lasers Eng. 48 (2010) 1119-1125, https://doi.org/10.1016/j.optlaseng.2009.12.020.

[27] Z. Sui, P.P. Leong, I.P. Herman, G.S. Higashi, H. Temkin, Raman analysis of lightemitting porous silicon, Appl. Phys. Lett. 60 (1992) 2086-2088, https://doi.org/10. 1063/1.107097.

[28] E. Kayahan, White light luminescence from annealed thin $\mathrm{ZnO}$ deposited porous silicon, J. Lumin. 130 (2010) 1295-1299, https://doi.org/10.1016/j.jlumin.2010. 02.042 .

[29] L. Tsybeskov, Ju.V. Vandyshev, P.M. Fauchet, Blue emission in porous silicon: oxygen-related photoluminescence, Phys. Rev. B 49 (1994) 7821-7824, https://doi. org/10.1103/PhysRevB.49.7821.

[30] A. Zarroug, Z. Bouznif, Z. Ben Hamed, L. Derbali, H. Ezzaouia, Optoelectronic effect of porous silicon surface treatment with samarium ions for different deposition times and characterizations, Int. J. Adv. Manuf. Technol. 93 (2017) 2403-2410, https://doi.org/10.1007/s00170-017-0600-y.

[31] M. Rahmani, A. Moadhen, A. Mabrouk Kamkoum, M.A. Zaïbi, R. Chtourou, L. Haji, M. Oueslati, Emission mechanisms in stabilized iron-passivated porous silicon: temperature and laser power dependences, Phys. B Condens. Matter 407 (2012) 472-476, https://doi.org/10.1016/j.physb.2011.11.018.

[32] A.S. Lenshin, P.V. Seredin, V.M. Kashkarov, D.A. Minakov, Origins of photoluminescence degradation in porous silicon under irradiation and the way of its elimination, Mater. Sci. Semicond. Process. 64 (2017) 71-76, https://doi.org/10 1016/j.mssp.2017.03.020.

[33] J. Knoester, J.E. Van Himbergen, On the theory of concentration self-quenching by statistical traps, J. Chem. Phys. 86 (1987) 3577-3582, https://doi.org/10.1063/1. 451962.

[34] D. Andsager, J. Hilliard, J.M. Hetrick, L.H. Abuhassan, M. Plisch, M.H. Nayfeh, Quenching of porous silicon photoluminescence by deposition of metal adsorbates, J. Appl. Phys. 74 (1993) 4783-4785, https://doi.org/10.1063/1.354350. 